\title{
Unusual Drainage of the Right Testicular Vein: A Case Report
}

\author{
Seth Gardner \\ Department of Natural and Social Sciences, Bowling Green State University Firelands, Huron, USA \\ Email: gardnes@bgsu.edu
}

Received 10 April 2015; accepted 12 June 2015; published 15 June 2015

Copyright (C) 2015 by author and Scientific Research Publishing Inc.

This work is licensed under the Creative Commons Attribution International License (CC BY). http://creativecommons.org/licenses/by/4.0/

c) (i) Open Access

\begin{abstract}
Routine dissection was carried out on a 75-year-old male cadaver and the drainage pattern of the testicular veins was identified and photographed. Dissection showed that the right testicular vein demonstrated an abnormal drainage pattern by terminating into the right renal vein. The left testicular vein demonstrated a normal drainage pattern by terminating into the left renal vein. The unusual drainage of the right testicular vein into the right renal vein may complicate hemodynamics thus causing a varicocele. Complications of a varicocele could lead to testis atrophy and/or infertility. Knowing the anatomical variants of the testicular veins drainage pattern may help the surgeon avoid potential complications during routine laparoscopic procedures and may also uncover a reason for male infertility.
\end{abstract}

\section{Keywords}

Testicular Veins, Gonadal Veins, Renal Veins, Varicocele

\section{Introduction}

Testicular veins arise from the pampiniform plexus of veins which is formed at the upper pole of the testis [1]-[3]. They travel through the spermatic cord and coalesce to form two or three veins. In the lumbar region, these veins combine and form a single testicular vein on the each side. These testicular veins then ascend a retroperitoneal path along the psoas major against the posterior abdominal wall [3]. The right and left testicular veins drainage patterns are anatomically asymmetric. This anatomical asymmetry induces hemodynamic differences in testicular vein. The right testicular vein usually drains into the inferior vena cava (IVC) in an oblique orientation whereas the left testicular vein typically drains into the left renal vein almost vertically [1]-[3]. This termination asymmetry could be significant by creating various pathologies. It is suspected that some variations of the drainage pattern could induce hemodynamic differences causing a varicocele [4]. Varicocele is the ab- 
normal dilatation of veins of pampiniform plexus within the substance of the testis causing testicular atrophy and also a suspected cause of male infertility [5] [6]. Its pathology occurs in approx. 15\% of the male population [6]. Varicocele has been shown to be much more common on the left [7] [8] and extremely rare on the right [9]. The following is a case report of the unusual drainage of the right testicular vein draining into the right renal vein.

\section{Material and Methods}

During routine educational dissection of a 75-year-old male, anomalous termination of the right testicular vein was identified. The cause of death in this individual was lung cancer. Using conventional dissecting techniques, the entire anterolateral abdominal wall was removed to provide free access to the posterior abdominal wall. Components of the urogenital system on the posterior abdominopelvic wall were identified and dissected finely to expose and separate the arteries and veins from surrounding organs. Following fine dissection, the entire urogenital system was removed from the posterior abdominopelvicwall and photographed. No other venous abnormalities were noted in this individual, however an abdominal aortic aneurysm was discovered during dissection.

\section{Results}

Many variations of the testicular veins have been demonstrated. Shown below (Figure 1) is the right testicular vein terminating into the right renal vein. The perpendicular trajectory may be responsible for a right sided varicocele.

\section{Discussion}

The testis is an important organ upon which the survival of the species depends. The testicular veins play major roles in the thermo-regulation that is essential for the efficient functioning of this organ [7]. Drainage of the testicular veins into the inferior vena cava on the right side and the left renal vein on the left side respectively, is the most constant pattern described in almost all the anatomy textbooks [1]-[3]. Left testicular vein draining into the left renal vein in perpendicular fashion seems to raise the hydrostatic pressure of left testicular vein which is transmitted to the pampiniform plexus of veins leading to its abnormal dilation [10]. While the right testicular vein usually draining into the IVC at an oblique angle, may help explain why varicocele is more common on the

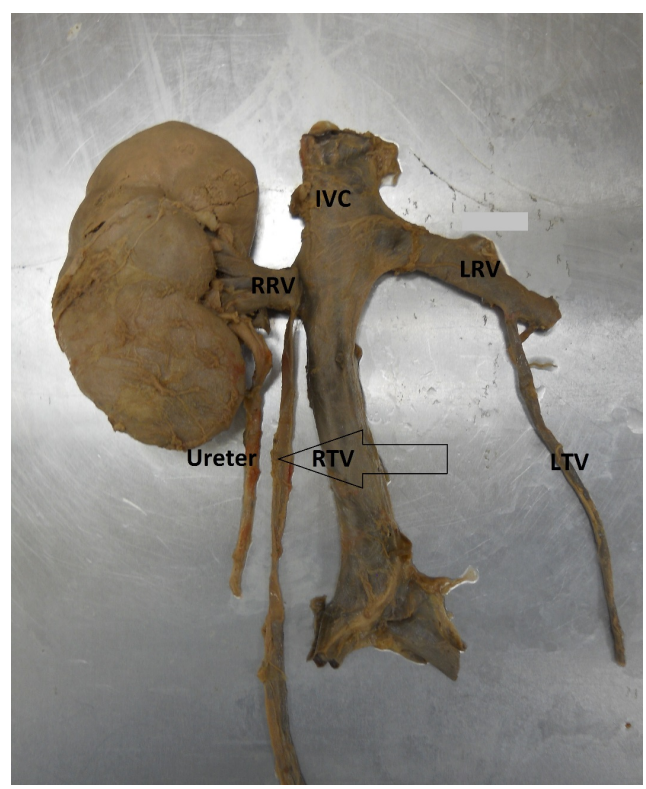

Figure 1. Photograph of the right testicular vein (RTV), at arrow, draining into the right renal vein (RRV), an anatomical variant, and the left testicular vein (LTV) draining into the left renal vein (LRV), a normal finding. 
left than the right [10]. The anatomical variations related to the testicular veins are more frequently found on the left side [11]. Variation of the right gonadal vein draining into the right renal vein is reported by only a few authors [12]. Bergman et al. reported this variation in 1.5\% or 4 out of 220 cases. This paper demonstrates another anomalous case of the right testicular vein terminating into the right renal vein. This variant drainage pattern may contribute to a varicocele on the right side. The varicocele is a well recognized cause of decreased testicular function and is known to be present in about $40 \%$ of infertile males [13]. During the developmental phases of the embryonic veins, a defect at any stage can result in altered anatomy of venous trunks which later develop as congenital vascular malformations [10]. Sadler reports the asymmetric drainage pattern of testicular veins is based on their mode of development. During this phenomenon of vena caval formation, the subcardinal veins undergo subsequent phases of evolution. The fetal subcardinal veins anastomose with each other. This anastomosis forms the left renal vein. This is followed by the disappearance of the left subcardinal vein and the only portion remaining is the most distal part that soondevelops into the left testicular vein. The right subcardinal vein forms the renal segment of IVC and right testicular vein [14] [15]. Resulting into the right testicular vein draining into the IVC. The cause of the testicular venous variations including the present case can be attributed to the anomalous dysplasia of fetal subcardinal veins during embryonic life [14].

\section{Conclusion}

In conclusion, this variation may not be clinically significant but knowledge of this type of variation becomes important for surgeons. Images with abnormal vascular drainage patterns may be incorrectly interpreted in the absence of knowledge of the variation in the drainage pattern of origin of these vessels. It is therefore noteworthy that for accurate diagnosis, variations in the origins, courses and relations of structures in these regions should be recognized. Surgical occlusion of the testicular veins especially the left testicular vein is the most popular treatment for varicocele.

\section{Conflict of Interest}

There is no conflict of interest.

\section{References}

[1] Moore, K.L. and Persaud, T.V.N. (2002) The Developing Human: Clinically Oriented Embryology. 7th Edition, WB Saunders, Philadelphia.

[2] Sadler, T.W. (2006) Langman’s Medical Embryology. 10th Edition, Development of Cardiovascular System, 186-189.

[3] Standring, S. (2008) Gray’s Anatomy: The Anatomical Basis of Clinical Practice. 40th Edition, Churchill Livingstone, London.

[4] Itoh, M., Moriyama, H., Tokunaga, Y., Miyamoto, K., Nagata, W., Satriotomo, I., Shimada, K. and Takeuchi, Y. (2001) Embryological Consideration of Drainage of the Left Testicular Vein into the Ipsilateral Renal Vein: Analysis of Cases of a Double Inferior Vena Cava. International Journal of Andrology, 24, 142-152. http://dx.doi.org/10.1046/j.1365-2605.2001.00286.x

[5] Gandhi, S., Sharma, M., Pakhiddey, R., Mehta, V., Suri, R.K. and Rath, G. (2013) Unilateral Aberrant Gonadal Venous Anatomy Coexistent with a Distinct Intrarenal Cleft. OA Anatomy, 1, 28. http://dx.doi.org/10.13172/2052-7829-1-3-896

[6] Braedel, H.U., Steffens, J., Ziegler, M., Polsky, M.S. and Platt, M.L. (1994) A Possible Ontogenic Etiology for Idiopathic Left Varicocele. Journal of Urology, 151, 62-66.

[7] Asala, S., Chaudhary, S.C., Masumbuko-Kahamba, N. and Bidmos, M. (2001) Anatomical Variations in the Human Testicular Blood Vessels. Annals of Anatomy, 183, 545-549. http://dx.doi.org/10.1016/S0940-9602(01)80064-9

[8] Rai, R. and Ranade, A.V. (2007) Anomalous Continuation of the Left Lateral Testicular Vein. Clinical Anatomy, 20, 988-989. http://dx.doi.org/10.1002/ca.20483

[9] Nayak, B.S., Rao, K.M., Shetty, S.D., Sirasanagandla, S.R., Kumar, N. and Guru, A. (2013) Terminal Bifurcation of the Right Testicular Vein and Left Testicular Arterio-Venous Anastomosis. Kathmandu University Medical Journal, 11, 168-170.

[10] Nagler, H.M., Luntz, R.K. and Martinis, F.G. (1997) Varicocele. Infertility in the Male. 3rd Edition, Mosbi Year Book, St. Louis.

[11] Bergman, R.A., Thompson, S.A., Afifi, A.K. and Saadeh, F.A. (1988) Compendium of Human Anatomic Variation, 
Text, Atlas and World Literature. Urban and Schwarzenberg, Munich.

[12] Nim, V.K. and Mohandas, K. (2010) Abnormal Drainage of the Right Testicular Vein. JIMSA, 23, 91.

[13] Beck, E.M., Schlegel, P.N. and Goldstein, M. (1992) Intraoperative Varicocele Anatomy: A Macroscopic and Microscopic Study. Journal of Urology, 148, 1190-1194.

[14] McClure, C.F.W. and Butler, E.G. (1925) The Development of the Vena Cava Inferior in Man. American Journal of Anatomy, 35, 331-383. http://dx.doi.org/10.1002/aja.1000350302

[15] Pansky, B. (1982) Development of the Venous System. Review of Medical Embryology. Macmillan Publishing Co., New York, 328-389. 